\title{
Dilution and slow injection reduces the incidence of rocuronium-induced withdrawal movements in children
}

\author{
Young Hee Shin, Chung Su Kim, Jong-Hwan Lee, Woo Seog Sim, Justin Sangwook Ko, Hyun Sung Cho, \\ Hui Yeon Jeong, Hye Won Lee, and Sang Hyun Kim \\ Department of Anesthesiology and Pain Medicine, Samsung Medical Center, Sungkyunkwan University School of Medicine, Seoul, \\ Korea
}

Background: The aim of this study was to evaluate whether slow injection of diluted rocuronium could reduce rocuronium-induced withdrawal movements effectively in children.

Methods: After loss of consciousness, rocuronium $0.6 \mathrm{mg} / \mathrm{kg}$ was administered into 171 children according to the pre-assigned groups as follows: Group CF, injection of non-diluted rocuronium over 5 seconds; Group CS, injection of non-diluted rocuronium over 1 minute; Group DF, injection of diluted rocuronium (10 times) over 5 seconds; Group DS, injection of diluted rocuronium over 1 minute. An investigator who was blind to the injection techniques recorded patient movements followed by rocuronium injection.

Results: The incidence of withdrawal movement in Group CF was highest among the groups (all $\mathrm{P}<0.0001$ ). Moreover, withdrawal movement was less frequently observed in Group DS than in Groups CS and DF (P = 0.021 and $\mathrm{P}=0.007$, respectively).

Conclusions: Slow injection of diluted rocuronium reduced the incidence of withdrawal movements in children. (Korean J Anesthesiol 2011; 61: 465-469)

Key Words: Child, Injections, Intravenous, Movement, Pain, Rocuronium.

Received: June 16, 2011. Revised: July 13, 2011. Accepted: July 22, 2011.

Corresponding author: Jong-Hwan Lee, M.D., Ph.D., Department of Anesthesiology and Pain Medicine, Samsung Medical Center, Sungkyunkwan University School of Medicine, 50, Irwon-dong, Gangnam-gu, Seoul 135-710, Korea. Tel: 82-2-3410-1928, Fax: 82-2-3410-0361, E-mail: jonghwanlee75@gmail.com

(c) This is an open-access article distributed under the terms of the Creative Commons Attribution Non-Commercial License (http:// creativecommons.org/licenses/by-nc/3.0/), which permits unrestricted non-commercial use, distribution, and reproduction in any medium, provided the original work is properly cited. 


\section{Introduction}

Rocuronium is frequently used to facilitate tracheal intubation during the induction of general anesthesia. However, rocuronium injections often produce withdrawal movements of the injected periphery or generalized movement related to injection pain [1-3]. Although there is no report of recall or complaint of rocuronium-related pain after anesthetic recovery, extreme movement during the induction of anesthesia can be potentially harmful to patients, especially in children. There was a case of pulmonary aspiration secondary to gastric regurgitation caused by generalized movement during rocuronium injection [4]. In addition, these rocuronium-related withdrawal movements appeared to occur more frequently in younger patients [5].

Numerous studies have reported various techniques to mitigate withdrawal movements during rocuronium injection including the use of drugs [5-12], dilution with $0.9 \% \mathrm{NaCl}$ [13], and slow infusion by a syringe pump [14]. However, these methods often require additional materials which seem cumbersome in the clinical settings. The aim of this prospective, randomized, and double-blinded study was to evaluate whether it was possible to reduce withdrawal movements to a similar degree observed in previously reported methods on pediatric patients using a combination of simple dilution and slow injection of rocuronium.

\section{Materials and Methods}

After obtaining our institutional review board approval (Ref: 2008-12-038-001) and written informed consent, a total of 171 American Society of Anesthesiologists (ASA) physical status I or II patients, aged $1-15$ years that were undergoing general anesthesia for elective surgery were enrolled in this study. The CONSORT guidelines were followed with respect to the reporting of this prospective, randomized, and double-blinded study. Rocuronium was approved by FDA for pediatric administration $(0.6 \mathrm{mg} / \mathrm{kg})$ as an adjunct to general anesthesia to facilitate tracheal intubation (http://www.accessdata.fda.gov/ drugsatfda_docs/label/2008/020214s030lbl.pdf). Patients with a history of neurologic deficit, known allergy to the trial drug, or asthma, and those who had received analgesics or sedative within the previous 24 hours were excluded from this study.

Patients were randomized using an internet-based computer program (http://www.randomizer.org) to one of four groups as follows: Group CF $(\mathrm{n}=43)$, fast injection over 5 seconds of non-diluted rocuronium (10 mg/ml); Group CS ( $\mathrm{n}=40)$, slow injection over 1 minute of non-diluted rocuronium (10 mg/ $\mathrm{ml})$; Group DF ( $\mathrm{n}=42)$, fast injection over 5 seconds of diluted rocuronium with maintaining solution ( $1 \mathrm{mg} / \mathrm{ml}$ ); Group DS (n
= 46), slow injection over 1 minute of diluted rocuronium with maintaining solution $(1 \mathrm{mg} / \mathrm{ml})$. Identical syringes were used for all injections.

No premedication was administered before surgery. In the wards, a 24-gauge intravenous cannula was inserted in one of either dorsum of the hands. Upon arrival in the operating room, clinical standard monitoring including electrocardiography, pulse oxymetry, and non-invasive blood pressure measurement were applied. In Group DF and Group DS, rocuronium was diluted using the maintaining intravenous solution $(0.9 \%$ $\mathrm{NaCl}$ or Ringer's lactate solution) when patients arrived in the operating room. All syringes were prepared by an investigator and were covered to hide the nature and amount of the solution.

Anesthesia was induced with $2.5 \%$ thiopental sodium ( $5 \mathrm{mg} / \mathrm{kg}$ body weight). After the loss of consciousness was confirmed by abolished eyelash reflex, mask ventilation with 2 vol\% seveoflurane in oxygen was started. Rocuronium $0.6 \mathrm{mg} /$ $\mathrm{kg}$ was administered according to the pre-assigned group into a rubber port connected directly to the intravenous cannula after end-tidal concentration of sevoflurane reached 2 vol\%. In all patients, the investigator kept hold of the prepared syringe for over 1 minute to prevent the observer from knowing the duration of the rocuronium injection. In addition, the injection was performed under the surgical table in all enrolled patients. The flow of the intravenous fluid was maintained at a rate of 5-7 $\mathrm{ml} / \mathrm{min}$ during the study period. No other drug was administered until completing the injection of rocuronium.

The blinded observer stood outside the operating room during the preparation of the syringe and assessed patient response during and immediately after rocuronium injection. The movement related to rocuronium injection was graded according to the four-point scale [3]: $1=$ no response, $2=$ movement at the wrist only, $3=$ movement involving the arm only (elbow or shoulder), and 4 = generalized movement or withdrawal in more than one extremity. A grade $\geq 2$ was considered as significant movement.

To detect a 50\%-difference in the incidence of rocuroniuminduced withdrawal movement, at least 32 patients per group were required at a significant level of 0.05 and a probability power of 0.8 based on the estimated incidence of $80 \%$. Data were presented as mean \pm SD or number of patients. Patient characteristics were compared by one-way analysis of variance or chi-square test, when indicated. The incidence of withdrawal response was analyzed using the Fisher's exact test. The Kruskal-Wallis test was used to compare the grade of movement and the multiple comparisons among groups were analyzed by the Mann-Whitney U test with Bonferroni's correction. SPSS 12.0 for Window (SPSS Inc., Chicago, IL, USA) was used for all statistical analysis. A $\mathrm{P}<0.05$ was considered statistically significant. 


\section{Results}

A total of 171 pediatric patients were enrolled in this study from June 2008 to March 2011. No patient was excluded from the study. There was no significant difference in patient characteristics among the different groups (Table 1) and there was no complication related to the study.

The overall incidences of withdrawal movement related to rocuronium injection in Groups CF, CS, DF and DS were 95.3\%, $47.5 \%, 50.0 \%$ and $21.7 \%$, respectively (Fig. 1). The incidences of withdrawal response in Groups CS, DF and DS were less frequent than that of Group CF (all P $<0.0001$ ) (Fig. 1). In addition, the incidence of withdrawal movement in Group DS was significantly less frequent than those in Groups CS and $\mathrm{DF}(\mathrm{P}=0.021$ and $\mathrm{P}=0.007$, respectively) (Fig. 1). Moreover, after multiple comparisons of the four groups, slow injection of diluted rocuronium was the most effective to reduce the grade of withdrawal movement (Table 2). There was no difference in reducing withdrawal response between the slow injection technique of undiluted rocuronium and fast injection technique of diluted rocuronium (Table 2). However, those two techniques were still more effective than the fast injection technique using undiluted rocuronium (Table 2).

\section{Discussion}

Our study showed that the combination of manual slow injection and simple dilution of rocuronium was effective in decreasing the incidence of withdrawal movement followed by rocuronium injection in pediatric patients.

The exact cause of rocuronium injection-induced withdrawal movement has not been elucidated, but the elicitation of pain has been ascribed as one of the important factors [2,3]. Several possible mechanisms of rocuronium-induced pain by

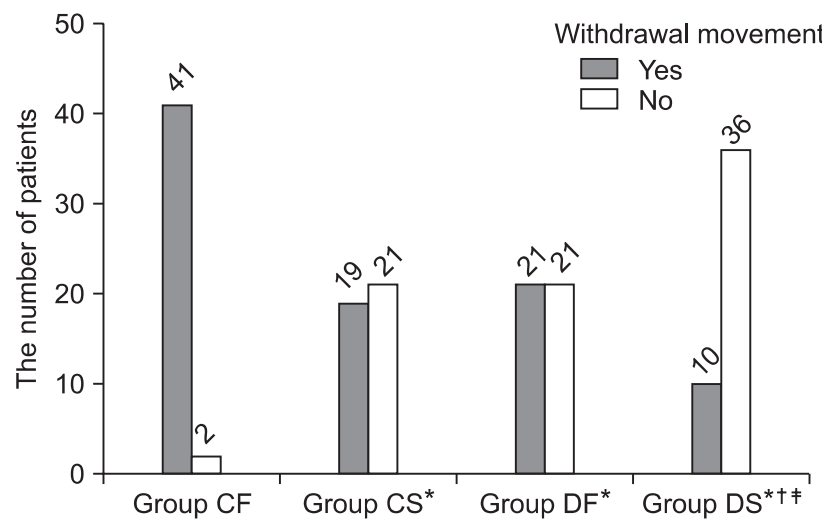

Fig. 1. Overall incidence of the withdrawal movements related to rocuronium injection. Group CF: fast injection over 5 seconds of non-diluted rocuronium (10 mg/ml), Group CS: slow injection over 1 minute of non-diluted rocuronium $(10 \mathrm{mg} / \mathrm{ml})$, Group DF: fast injection over 5 seconds of diluted rocuronium with maintaining solution $(1 \mathrm{mg} / \mathrm{ml})$, Group DS: slow injection over 1 minute of diluted rocuronium with maintaining solution $(1 \mathrm{mg} / \mathrm{ml})$. Values are number of patients (\% incidence), which are displayed in the middle of bars. ${ }^{*} \mathrm{P}<0.0001$ versus Group CF. ${ }^{\dagger} \mathrm{P}=0.021$ versus Group CS. ${ }^{\ddagger} \mathrm{P}=0.007$ versus Group DF.

Table 1. Characteristics of Patients in this Study

\begin{tabular}{lcccc}
\hline & Group CF $(\mathrm{n}=43)$ & Group CS $(\mathrm{n}=40)$ & Group DF $(\mathrm{n}=42)$ & Group DS (n=46) \\
\hline Age $(\mathrm{yr})$ & $6.1(4.2)$ & $7.1(4.5)$ & $6.8(3.7)$ & $6.4(4.2)$ \\
Weight $(\mathrm{kg})$ & $25.1(15.9)$ & $28.6(17.0)$ & $27.2(15.6)$ & $28.2(16.1)$ \\
Male/Female & $36 / 7$ & $28 / 12$ & $28 / 14$ & $33 / 13$ \\
\hline
\end{tabular}

Values are means (SD) or numbers of patients. Group CF: fast injection over 5 seconds of non-diluted rocuronium (10 mg/ml), Group CS: slow injection over 1 minute of non-diluted rocuronium $(10 \mathrm{mg} / \mathrm{ml})$, Group DF: fast injection over 5 seconds of diluted rocuronium with maintaining solution ( $1 \mathrm{mg} / \mathrm{ml})$, Group DS: slow injection over 1 minute of diluted rocuronium with maintaining solution $(1 \mathrm{mg} / \mathrm{ml})$. There is no difference among the groups.

Table 2. Grade of Withdrawal Movement Related to Rocuronium Injection

\begin{tabular}{lcccc}
\hline & Group CF $(\mathrm{n}=43)$ & Group CS* $(\mathrm{n}=40)$ & Group DF* $(\mathrm{n}=42)$ & Group DS*,, (n $=46)$ \\
\hline 1 (no response) & $2(4.7)$ & $21(52.5)$ & $21(50.0)$ & $36(78.3)$ \\
2 (wrist) & $3(7.0)$ & $11(27.5)$ & $11(26.2)$ & $8(17.3)$ \\
3 (elbow/shoulder) & $10(23.3)$ & $7(17.5)$ & $7(16.7)$ & $1(2.2)$ \\
4 (generalized) & $28(65.1)$ & $1(2.5)$ & $3(7.1)$ & $1(2.2)$ \\
\hline
\end{tabular}

Values are number of patients (\% incidence). Group CF: fast injection over 5 seconds of non-diluted rocuronium (10 mg/ml), Group CS: slow injection over 1 minute of non-diluted rocuronium $(10 \mathrm{mg} / \mathrm{ml})$, Group DF: fast injection over 5 seconds of diluted rocuronium with maintaining solution $(1 \mathrm{mg} / \mathrm{ml})$, Group DS: slow injection over 1 minute of diluted rocuronium with maintaining solution $(1 \mathrm{mg} / \mathrm{ml})$. The movements followed by rocuronium injection were graded according to the four-point scale: $1=$ no response, $2=$ movement at the wrist only, $3=$ movement involving the arm only (elbow or shoulder), and $4=$ generalized movement or withdrawal in more than one extremity. $* \mathrm{P}<0.01$ versus Group CF. ${ }^{\dagger} \mathrm{P}<0.05$ versus Group CS. ${ }^{\dagger} \mathrm{P}<0.05$ versus Group DS. All $\mathrm{P}$ values were adjusted by Bonferroni's correction. 
activation of nociceptors include: 1) by the un-physiological osmolality or low $\mathrm{pH}$ of rocuronium solution, 2) by the release of endogenous mediators, such as histamine or bradykinin, or 3) by the allogenic effect of aminosteroidal neuromuscular blocking drugs $[2,6,9]$. However, regardless of its mechanism, the prevention of withdrawal movements during rocuronium injection is especially important in pediatric patients because severe movement can easily dislodge the intravenous cannula and re-cannulation itself is a time-consuming and sometimes very difficult procedure because of tiny vessels and extensive subcutaneous fat tissue. In addition, if the condition of the patient is unstable, dislodgement of intravenous cannula and the delay of re-cannulation would be very harmful to the patients. Moreover, especially in pediatric patients, the generalized movement itself could be fatal because it can cause pulmonary aspiration following gastric regurgitation [4].

To reduce withdrawal movements induced by rocuronium injection, various techniques have been introduced. However, all previous methods need additional drugs [7,10-12,15$17]$, mixing solutions $[13,18]$, and devices [14], which are not essentially required during general anesthesia induction. In addition, mixing different drugs and increasing the number of administered drugs may be potentially problematic [19]. Compared to the previously described techniques, our combination technique appears to be more practical in clinical settings because it does not require any additional device, drugs, or solutions. In fact, all materials which we used in this study were essentially needed for rocuronium injection. Moreover, our technique can be modified to simple slow injection of rocuronium through fully-dripped maintaining intravenous solution in clinical anesthesia.

Our injection protocol was derived from two previous techniques including dilution of rocuronium with $0.9 \% \mathrm{NaCl}$ [13] and slow infusion of rocuronium using a syringe pump [14]. However, those studies are different form our study because the category of patients in those studies were only adults and they showed higher incidences of withdrawal movements than the subjects in our study [1,2].

Overall incidence of withdrawal movement in our patients who underwent the combination technique (Group DS) was $21.7 \%$. The result was similar with the previous study [8] where the incidence was $23 \%$ using pretreatment of remifentanil in children. The comparable outcomes between the two studies suggest that our combination technique may be considered as more clinically applicable in pediatric patients. In addition, the overall incidence of withdrawal movement related to rocuronium injection was $95.3 \%$ in the control group (Group $\mathrm{CF}$ ). This result was also consistent with the previous results where the incidence was 83 to $100 \%[3,9,14,20]$. Although the simple dilution technique (Group DF) in our study showed a higher incidence of withdrawal movement than in the previous study [13] where diluted rocuronium with $0.9 \% \mathrm{NaCl}$ was applied in adults, this result may be caused by the relatively low incidence of withdrawal movement in adult patients, compared with pediatric patients $[10,21]$.

There are several limitations in this study. First, $\mathrm{pH}$ of diluted rocuronium was not measured. However, it was already suggested that $\mathrm{pH}$ 4-adjusted saline did not trigger the injection pain in previous studies [2]. Moreover, Tuncali et al. [13] reported that the dilution of rocuronium with $0.9 \% \mathrm{NaCl}$ did not change its $\mathrm{pH}$ and osmolality. Therefore, we believed that the $\mathrm{pH}$ of our diluted solution had little effect on the results of this study. Second, we did not apply our technique to adult patients. Considering the low incidence ( 12 to $28 \%$ ) of withdrawal movement related to rocuronium injection in adults $[10,21]$, the results may be different from our results in children. Further studies are needed to evaluate the effect of our technique in adult patients. Third, the injection speed of rocuronium was divided as fast or slow based on the injection time without considering the total amount of rocuronium. In addition, the speed of rocuronium injection may be inconsistent because we did not use any device to assess it. Those two confounding factors would affect the results in this study. However, the aim of this study was to find the simplest technique to decrease withdrawal movement during rocuronium injection. Therefore, our manual slow injection technique using diluted rocuronium may not be precise and warrant further investigation, but it still appears to be clinically usable. Lastly, we did not compare our technique to the various reported methods using different drugs directly. However, the incidence of withdrawal movements in our simple technique (Group DS) was in accordance with the previous study which used remifentanil in children. Therefore, we believed that our technique had a similar effect of reducing the incidence of withdrawal movement, compared with previous methods.

In conclusion, our manual slow injection of diluted rocuronium could significantly reduce the incidence of withdrawal movement to a similar degree reported previously in pediatric patients. Therefore, we recommend our method as a daily usable technique of rocuronium injection for reducing withdrawal movement in pediatric patients because of its simplicity and availability.

\section{References}

1. Steegers MA, Robertson EN. Pain on injection of rocuronium bromide. Anesth Analg 1996; 83: 203.

2. Borgeat A, Kwiatkowski D. Spontaneous movements associated with rocuronium: is pain on injection the cause? Br J Anaesth 1997; 79: 382-3.

3. Shevchenko Y, Jocson JC, McRae VA, Stayer SA, Schwartz RE, 
Rehman M, et al. The use of lidocaine for preventing the withdrawal associated with the injection of rocuronium in children and adolescents. Anesth Analg 1999; 88: 746-8.

4. Lui JT, Huang SJ, Yang CY, Hsu JC, Lui PW. Rocuronium-induced generalized spontaneous movements cause pulmonary aspiration. Chang Gung Med J 2002; 25: 617-20.

5. Borgeat A, Kwiatkowski D, Ruetsch YA. Spontaneous movements associated with rocuronium injection: the effects of prior administration of fentanyl. J Clin Anesth 1997; 9: 650-2.

6. Ahmad N, Choy CY, Aris EA, Balan S. Preventing the withdrawal response associated with rocuronium injection: a comparison of fentanyl with lidocaine. Anesth Analg 2005; 100: 987-90.

7. Cheong KF, Wong WH. Pain on injection of rocuronium: influence of two doses of lidocaine pretreatment. Br J Anaesth 2000; 84: 106-7.

8. Kim JY, Kim JY, Kwak HJ. Pretreatment with remifentanil to prevent withdrawal after rocuronium in children. Br J Anaesth 2007; 98: 120-3.

9. Liou JT, Hsu JC, Liu FC, Ching-Wah Sum D, Lui PW. Pretreatment with small-dose ketamine reduces withdrawal movements associated with injection of rocuronium in pediatric patients. Anesth Analg 2003; 97: 1294-7.

10. Memiş D, Turan A, Karamanlioğlu B, Süt N, Pamukçu Z. The prevention of pain from injection of rocuronium by ondansetron, lidocaine, tramadol, and fentanyl. Anesth Analg 2002; 94: 1517-20.

11. Oh AY, Seo KS, Goo EK, Park YO, Kim SJ, Kim JH. Prevention of withdrawal movement associated with injection of rocuronium in children: comparison of remifentanil, alfentanil and fentanyl. Acta Anaesthesiol Scand 2007; 51: 1190-3.

12. Turan A, Memis D, Karamanlioglu B, Sut N, Pamukcu Z. The prevention of pain from injection of rocuronium by magnesium sulphate, lignocaine, sodium bicarbonate and alfentanil. Anaesth Intensive Care 2003; 31: 277-81.

13. Tuncali B, Karci A, Tuncali BE, Mavioglu O, Olguner CG, Ayhan S, et al. Dilution of rocuronium to $0.5 \mathrm{mg} / \mathrm{ml}$ with $0.9 \% \mathrm{NaCl}$ eliminates the pain during intravenous injection in awake patients. Anesth Analg 2004; 99: 740-3.

14. Baek SH, Woo CM, Lee HJ, Yoon JY, Kwon JY, Shin SW. Rocuroniuminduced withdrawal movements associated with different Rocuronium injection method. Paediatr Anaesth 2008; 18: 515-9.

15. Joshi GP, Whitten CW. Pain on injection of rocuronium bromide. Anesth Analg 1997; 84: 228.

16. Reddy MS, Chen FG, Ng HP. Effect of ondansetron pretreatment on pain after rocuronium and propofol injection: a randomised, double-blind controlled comparison with lidocaine. Anaesthesia 2001; 56: 902-5.

17. Ruetsch YA, Borgeat A. Withdrawal movements associated with the injection of rocuronium. Anesth Analg 2000; 90: 227-8.

18. Han DW, Koo BN, Choi SH, Lee JS, Shin YS, Sharma M, et al. Neutralized rocuronium ( $\mathrm{pH}$ 7.4) before administration prevents injection pain in awake patients: a randomized prospective trial. J Clin Anesth 2007; 19: 418-23.

19. Dalgleish DJ. Drugs which cause pain on intravenous injection. Anaesthesia 2000; 55: 828-9.

20. Kim KS, Kim YS, Jeon WJ, Yeom JH. Prevention of withdrawal associated with the injection of rocuronium in adults and children. J Clin Anesth 2006; 18: 334-8.

21. Mencke T, Schreiber JU, Knoll H, Stracke C, Kleinschmidt S, Rensing $\mathrm{H}$, et al. Women report more pain on injection of a precurarization dose of rocuronium: a randomized, prospective, placebo-controlled trial. Acta Anaesthesiol Scand 2004; 48: 1245-8. 